\title{
Research on the Adjustment of Industrial Structure under Financial Guidance
}

\author{
Zhiwei Yan \\ School of Economics and Management, Beijing Jiaotong University, Beijing 100044, China \\ 15120503@bjtu.edu.cn \\ *Zhiwei Yan
}

Keywords: Rationalization of industrial structure, Industrial structural upgrade, Financial support.

\begin{abstract}
The optimization and upgrading of industrial structure is a breakthrough in the current economic growth, and financial as the core of economic development, in the process of industrial restructuring play an important role. This paper explores the mechanism of financial capital and industrial structure adjustment, and uses the OLS model to study the guiding role of financial funds on industrial structure adjustment in China from 2000 to 2015. The research shows that the financial support of the financial system promotes the process of industrial optimization and upgrading, among which the bank credit and financial investment in the form of financial integration are the main form. But the guiding role of the government monetary policy and risk guarantee are not obvious, which need to be further strengthened.
\end{abstract}

\section{Introduction and Literature Review}

At present, China's economic growth has changed from total growth to structural reform, especially the problem of industrial structure has seriously affected the development of China's economy. And financial as the basis and core of economic development, plays a very important role in the process of industrial restructuring, which could not be separated from the financial system support. Therefore, it is very important to study the impact of finance on industrial structure adjustment.

This paper puts forward the new direction of financial support for the adjustment of industrial structure from the guidance of financial funds, and improves the index measure of industrial structure adjustment. Through the establishment of relevant models, we validate the support of financial funds to support industrial structure adjustment effect.

\section{The Mechanism of Financial Guidance for Industrial Structure Adjustment}

This paper summarizes the aspects of financial capital impact on industrial restructuring, which are as follows:

(1) The capital formation of bank credit. The redistribution of funds generated by bank credit is achieved through the distribution of different industries, to achieve the purpose of promoting the development of high-quality industries.

(2) The guidance of funds under money supply. The central bank using monetary policy tools and interest rate policy to guide the capital investment, changing the distribution of funds in different industries.

(3) The financing promotion of capital market. The direct financing behavior of the asset market has accelerated the allocation of funds and promoted the adjustment of the industrial structure.

(4) The risk protection role of insurance. The risk dispersion mechanism of the financial system can speed up the technological progress and economic growth, and provide the corresponding financial risk guarantee for the industrial development. 


\section{The Measurement and Present Situation of China 's Industrial Structure Adjustment}

3.1 Measurement of Industrial Structure Adjustment Index. In view of the problems existing in the industrial structure of China, the industrial structure adjustment measures proposed in this paper include the rationalization of industrial structure and the high level of industrial structure.

(1) Rationalization of the industrial structure. It refers to the proportion of the proportion of the industry, on the one hand reflects the degree of coordination between industries on the other hand also reflects the degree of effective use of resources. In this paper, based on the study of Gan Chunhui (2011), we have redefined the rationalization formula of industrial structure(TE):

$$
T E=\sum_{i=1}^{3} \frac{Y_{i}}{Y} \times\left|\ln \left(\frac{Y_{i}}{Y} / \frac{L_{i}}{L}\right)\right|_{(1)}
$$

(2) High level of industrial structure. It reflects the upgrading of industrial structure. In the current industry development status of information technology-driven, the service of economic structure has become an important measure of industrial structure upgrading, and it is an important phenomenon in the process of "economic service" The growth rate of the tertiary industry is faster than that of the secondary industry (Wu Jinglian, 2008). Therefore, we use the ratio of the output value of the tertiary industry and the output value of the secondary industry (TS)to measure the degree of industrial structure upgrading. If the value of TS continues to increase, it means that the economy in the direction of service development, indicating that the industrial structure in the upgrade.

3.2 The Present Situation and Characteristics of China 's Industrial Structure. Fig.1. reflects the three-industrial added value over the years. It can be found that the three industries accounted for the proportion of the national economy has been changing, of which the first industry output value increased year by year and the second and third industry output growth is more rapid. One of the significant changes in the year since the beginning of 2012, the tertiary industry added value for the first time more than the secondary industry, has become China's economic development in the leading industries.

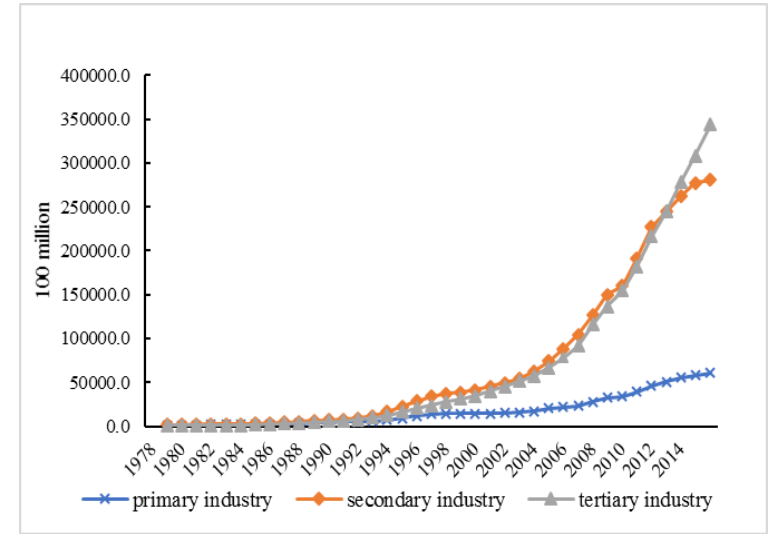

Fig.1. The growth trend of three-industrial output value

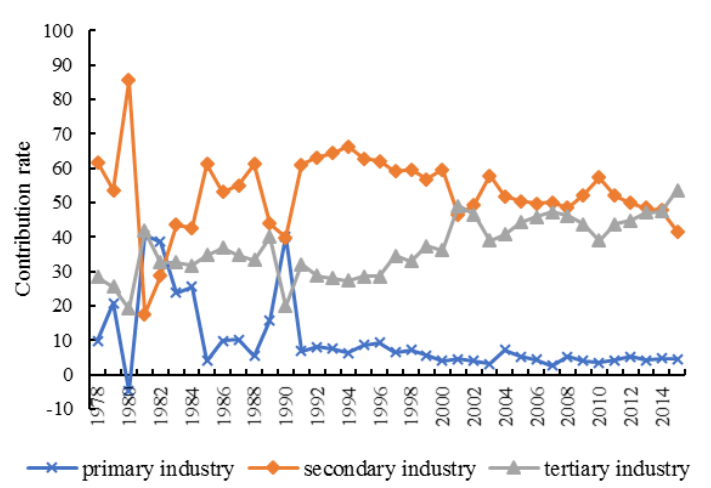

Fig.2. The contribution rate of three industries to GDP growth 
(1) Y represents the output value, $\mathrm{L}$ represents the number of people employed, and i represents the different industry

In addition, from the growth rate of GDP growth in various industries (Fig.2.), it can also be found that the contribution of the primary industry to GDP growth is declining year by year, and the contribution of the secondary industry to GDP growth is also declining in constant volatility, while the tertiary industry's contribution to GDP growth is increasing. The development of the tertiary industry has gradually occupied the leading position of China's economy, China's industrial structure is changing. With the position of second and tertiary industry changing in the national economy, China has entered the stage of industrialization of the late stage of development.

However, there are still many problems in China's industrial structure. The employment of the primary industry is still beyond its level, and the number of employment in the tertiary industry is obviously insufficient. there is a mismatch between the industrial structure and the employment structure, and the imbalance between supply and demand also hinders the healthy development of the economy. China's industrial restructuring stage is still facing a severe test.

Social reality tells us that China's industrial structure adjustment is not smooth sailing, but full of twists and turns. Industrial structure optimization and upgrading is also stumbling slowly. Fig.3. reflects China's development trend of industrial structure optimization and the upgrading from 1978 to 2015 .

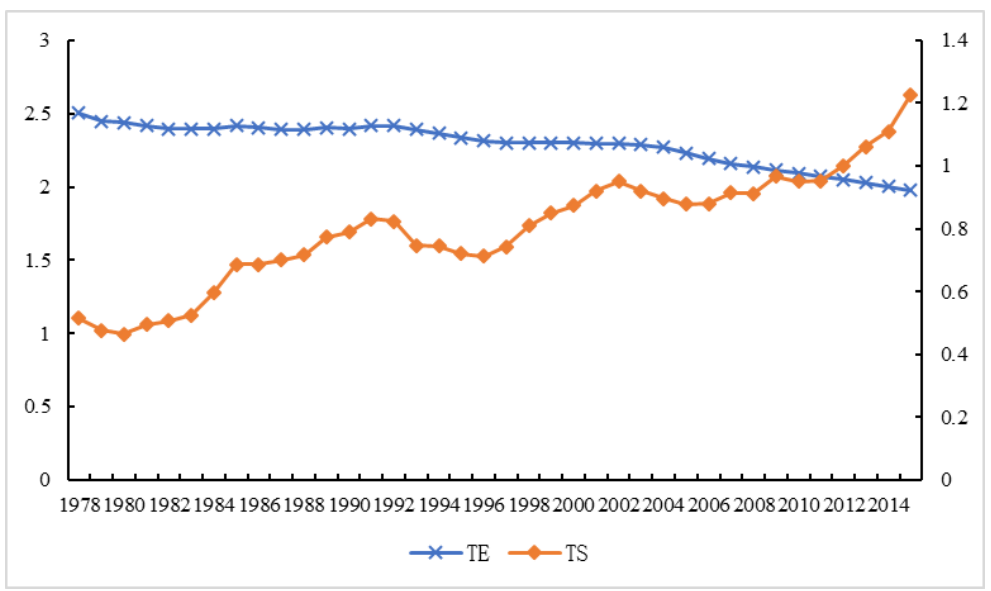

Fig.3. The Trend of Industrial Structure Optimization and Upgrading

\section{Model, Method and Empirical}

4.1 Mode Setting and Method. This paper aims to study the financial capital in the process of industrial restructuring in the guiding role, that is, in the process of industrial structure optimization and upgrading, financial funds play a role, but also in what areas play a role. For the analysis of such factors, we mainly use the method of metrological regression. But usually the original economic data is non-stationary, which cannot be directly regression operation. We need to make simple data processing.

4.2 Variables and Data. For the regression study of this paper, the dependent variable is the index of industrial structure adjustment. In this study, the TE index and TS index described above are used to represent the degree of optimization and upgrading. The independent variable is the financial capital guidance index. The choice of independent variables is based on the mechanism of financial capital in the adjustment of industrial structure, from the banking, securities market, insurance and the central bank four aspects of the financial support role was expressed. The corresponding indicators are: credit contribution index X1 (financial institution loan balance / GDP), capital market contribution index X2 ((stock market value + non-financial corporate credit) / GDP), insurance contribution index X3 (premium income / GDP) And the monetary contribution index X4 (M2 / GDP). We obtained the relevant data from 2000 to 2015, and the data were "China Statistical Yearbook" and "China Financial Yearbook" (2000-2016), and the indexes were logarithmically processed. 
4.3 Empirical analysis. The regression model was established with TE and TS indices as dependent variables respectively. The results are as follows:

$$
\begin{aligned}
& \ln (\mathrm{TE})=0.9166+0.2639 \ln \mathrm{X} 1-0.0334 \ln \mathrm{X} 2+0.0314 \ln \mathrm{X} 3-0.5309 \ln \mathrm{X} 4 \\
& \begin{array}{llll}
(19.17) \quad(2.66) \quad(-4.55) \quad(0.97) \quad(-4.08)
\end{array} \\
& \ln (\mathrm{TS})=0.1845-0.0150 \ln \mathrm{X} 1+0.0308 \ln \mathrm{X} 2-0.1567 \ln \mathrm{X} 3+0.1185 \ln \mathrm{X} 4
\end{aligned}
$$

$$
\begin{array}{llll}
(1.34) \quad(-0.07) \quad(2.05) \quad(-2.12) \quad(0.43)
\end{array}
$$

From the result, we find that only $\ln X 3$ did not pass the test at the $10 \%$ significant level, indicating that the impact of the insurance industry is not effective in industrial structure optimization. While the impact of bank credit, capital market financing and the central bank have a significant impact on industrial structure optimization. Furthermore, the impact of the role of bank credit is positive, while the capital market and the central bank financing is hindering optimization of industrial structure to a certain extent. For the industrial structure upgrade, we can know that only $\ln X 2$ and $\ln X 3$ have passed the test, indicating that the capital market financing and insurance industry risk protection show a significant impact on the industrial structure upgrading. However, the impact of bank credit and money supply is not reflected.

\section{Conclusions and Suggestions}

The research of this paper shows that the process of industrial structure adjustment is tortuous, and there are still many problems to be solved. And, the role of financial funds in the adjustment of industrial structure is not obvious, only the bank credit and capital market financing has played a significant role, while the impact of the policy guidance and risk support is not obvious. This is consistent with the development of China's financial system. China's bank-led institution's credit system will inevitably affect the financing of high-quality enterprises in all aspects of the industry. Bank loans have become the main source of funds for the development of these high-tech and high value-added enterprises. And the imperfect capital market has also led to these innovative small and medium enterprises is difficult to obtain financing. As a risk prevention agency, the insurance company's innovation to the innovative enterprise needs to be strengthened.

\section{References}

[1] Patrick H.T. Financial Development and Economic Growth in Undeveloped Countries, Economic Development and Cultural Change, vol 134(4), pp.174 -189, 1966.

[2] Darin, Hellmann. Banks as Catalysts for Industrialization, Journal of Financial Intermediation, vol 11, 2002.

[3] ZHENG Nan-yuan, YOU zhai, HE Cong. Study on the Mechanism of Financial Support Industry Structure Adjustment, Western Finance, vol 07, pp. 22-25, 2007.

[4] MAZhili. An Empirical Study on the Influence of Financial Development on Industrial Structure Optimization, Journal of Fi-nance and Economics Research, vol 6, pp. 10-14, 2011.

[5] Guo Xiaoli. An Empirical Study on the Relationship between Financial Development and Industrial Structure Adjustment - Tak-ing Beijing as an Example, Technology Economics and Management Research; vol 07, pp. 94-97, 2011.

[6] Wang Liguo, Zhao Wanyu. Study on Financial Development and Industrial Structure Upgrading in China, Journal of Finance and Economics, vol 01, pp. 22-29, 2015.

[7] Gan Chunhui, Zhang Ruogu, Yu Chentian. Effects of China's Industrial Structure Change on Economic Growth and Fluctua-tion, Journal of Economic Research, vol 05, pp. 16-31,2011.

[8] Li Xiaoping, Lu Xianxiang. Structural changes in China's manufacturing industry and productivity growth, World Economy, vol05, pp,52-64,2007. 
[9] Chen Yilin. Wu Jinglian: "China's growth model choice", Public Administration Review, vol 02, pp.155-157,2006. 